\title{
Educação e complexidade: um diálogo possível
}

Elza Maria Neffa Vieira de Castro* Universidade do Estado do Rio de Janeiro

Krishna Neffa Vieira de Castro** Universidade do Estado do Rio de Janeiro

Resumo Por supor que a filosofia de Paulo Freire se encontra impregnada de elementos de complexidade, um dos princípios da transdisciplinaridade, este artigo analisa as premissas do pensamento complexo identificando suas aproximações com os pressupostos freirianos, entendidos como elementos organizadores do conhecimento e estimuladores do espírito problematizador-criativo dos sujeitos históricos atuantes na educação brasileira. $\mathrm{O}$ estudo aponta elementos da abordagem transdisciplinar no pensamento de Paulo Freire por ele vislumbrar a educação como caminho de autonomia e libertação, a partir de um método de ensino entendido como campo de construção de conhecimento que incorpora a dimensão ontológica do ser humano e a prática educativa formadora de um sujeito transdisciplinar comprometido com a geração de novas estratégias articuladas ao bem comum em um processo contínuo de aprendizagem e de atuação política.

PALAVRAS-CHAVE: Educação; Complexidade; Sujeito transdisciplinar. 


\section{Education and complexity: a possible dialogue}

Abstract By assuming that Paulo Freire's philosophy is impregnated with elements of complexity, one of the principles of interdisciplinary methodology, this article aims to examine the principles of the complex thought in an attempt to identify their similarities with Freire's assumptions. They can be recognized as organizing elements of knowledge as well as stimulants of the problem solving-creative spirit of historic subjects acting in brazilian education. The bibliographical study shows that Paulo Freire absorbs the transdisciplinary approach when he envisions education as a path towards autonomy and liberation. Freire views it as a teaching method, not only as a construction field of knowledge which incorporates the ontological dimension of the human being, but also as an educational practice which enables the emergence of a transdisciplinary subject committed to the generation of new strategies that aim the common good in a continuous process of learning and political action.

KEYWORDS: Education; Complexity; Transdisciplinary subject.

\section{Introdução}

Com o intuito de contribuir para uma reflexão teórica, este artigo analisa os fundamentos filosóficos do educador Paulo Freire à luz da categoria da complexidade ${ }^{1}$, por entender que seus pressupostos se encontram impregnados de elementos do pensamento complexo, um dos princípios da metodologia transdisciplinar.

A reflexão sobre o pensamento freireano com base na categoria da complexidade parte do pressuposto de que se trata de um conjunto de estudos e de hipóteses convergentes que, mais do que responder a indagações, pretende suscitar debates marcados por conhecimentos ressignificados.

Paulo Freire criou o Método de Educação de Jovens e Adultos no Brasil e ao pressupor o ser humano como ser ativo que numa atitude de compromisso consigo mesmo e com o outro, estabelece relações amorosas e atos de liberdade produzindo cultura, abriu novas perspectivas para a educação e para o povo brasileiro: a possibilidade de ressignificar sua identidade construindo cidadania.

Como campo de construção de conhecimento, que incorpora a dimensão ontológica do ser humano (por identificá-lo como ser incompleto que se integra ao mundo querendo sempre mais), como método de ensino, que se baseia na ação-reflexão-ação, e como prática educativa, que possibilita a inserção crítica do sujeito na história ao fazer e refazer o mundo e a si mesmo em um processo contínuo de aprendizagem e de atuação política consciente e criadora, Paulo Freire entende a educação como caminho de autonomia e libertação e, por isso, pode-se supor que o seu pensamento impregna-se da abordagem transdisciplinar. 
O reconhecimento da transdisciplinaridade no pensamento de Paulo Freire resulta da percepção de que sua pedagogia e seu método transcendem à educação formal, alargando-se para uma concepção que insiste na implementação de atos de criação de uma nova realidade; na necessidade de ler o mundo, contextualizando o conhecimento significativo oriundo da atividade humana construída no compromisso de transformação da situação de dominação e de exclusão; na busca do diálogo com o Outro confrontando olhares para alcançar à solidariedade por meio de uma ação comunicativa, relacional, afetiva, consciente, esperançosa e emancipadora, que se insere no projeto de vida do sujeito que aprende a pensar e a ser compreensivo e solidário contra a desumanização de uma ordem socialmente injusta.

$\mathrm{Na}$ sociedade contemporânea, a produção do cidadão que é sujeito de sua própria formação representa um desafio para as instituições e para os educadores, na medida em que a educação se situa nas fronteiras do conhecimento e apresenta-se como uma estratégia para o desenvolvimento humano e para a construção de uma sociedade sustentável.

\section{Aproximações das bases filosóficas de Paulo Freire com os pressupostos epistemológicos do pensamento complexo de Edgar Morin}

Embora Paulo Freire postule sua filosofia permeada por uma lógica dialética com foco na construção de uma proposta educacional, cuja práxis se insere na realidade brasileira, e Edgar Morin discuta centralmente a epistemologia com foco na construção do método da complexidade postulando a discussão educacional como conseqüência dessa elaboração teórica, vislumbram-se algumas aproximações e complementaridades entre ambas, com base numa lógica complexa, tendo em vista a referência à compreensão da dinamicidade da realidade e à concepção problematizadora da educação baseada na relação consciência-mundo que ambos apontam. A análise dos pressupostos de Paulo Freire e de suas aproximações com as premissas do pensamento complexo de Edgar Morin constitui-se, nesse estudo, uma tentativa de identificar os princípios organizadores do conhecimento que são capazes de estimular o espírito problematizador dos sujeitos históricos atuantes na sociedade contemporânea.

A categoria da complexidade tem suscitado inúmeros mal-entendidos, dentre eles, a sua compreensão como completude do pensamento científico, por ser concebida como uma resposta em vez de ser considerada como desafio e como motivação para se pensar o sujeito e o mundo contemporâneo. Segundo Morin, tal mal-entendido resulta do fato de que a complexidade luta contra a mutilação e tenta conceber a articulação, a interrelação, as implicações mútuas, a identidade e a diferença dos aspectos físicos, biológicos, sociais, culturais, psíquicos e espirituais, tendendo para o conhecimento multidimensional que inclui a percepção poética e a sacralização da natureza. Para o sociólogo francês, o pensamento complexo é um pensamento que pratica o abraço e se prolonga na ética da solidariedade. Esta definição surge do conceito complexus, do latim plecto, plexi, complector, plexus, que significa tecido, trançado, enroscado, enlaçado, ou seja, "o que tece em conjunto", no sentido de unificação de diversas vias (desordem, contradição, problemas de organização etc.) sem destruição das suas 
autonomias, singularidades e diversidades, correspondendo ao verbo latino complexere: "abraçar" (MORIN, 1997, p. 11).

A proposta de religação das noções sobre a matéria, a vida, o ser humano e a sociedade evoca a complexidade como uma categoria capaz de rejuntar os conhecimentos e os fragmentos em que o ser humano se desfez para conceber uma humanidade plena, integral que, em consonância biofísica e histórica com o planeta, revele uma nova ordem cósmica construída a partir de uma sensibilidade que possibilite aos sujeitos superarem visões fragmentadas e vivências descontextualizadas. Nessa nova ordem, o Universo, o sistema-Terra e o fenômeno humano, concebidos como totalidades dinâmicas compostas de diversidades organicamente interligadas em sistemas abertos, são marcados pela auto-organização que combina, descombina e recombina a ordem, a desordem, a interação e a organização. A constituição de um sistema a partir da noção de um todo organizado e unido de elementos diferentes, singulares (átomos, moléculas, astros, seres vivos, ecossistemas, biosfera, sociedade e humanidade), permite sua formulação como uma unidade e como uma heterogeneidade, que se ordena, simultaneamente, em diversas perspectivas contraditórias (MORIN, 1977).

$\mathrm{Na}$ ótica do pensamento complexo, o ser humano é percebido como um cosmo que incorpora as dimensões biofísicas e psicossocioculturais e reflete uma natureza multidimensional de espécie-indivíduo, sociedade-indivíduo, homo sapiens-homo demens, que se permeia do pensamento racional, objetivo, empírico, preciso, conceitual, científico e do pensamento simbólico, mitológico, mágico, nos quais se mesclam aspirações, sentimentos, intuições, sonhos e loucuras.

A partir da noção de individualidade e de autonomia dependente do meio ambiente biológico, sociológico ou cultural, Morin (2000) concebe o ser humano como o único ser vivo na Terra que dispõe de um aparelho neurocerebral supercomplexo (capaz de subjetivar-se no ato da percepção, da representação, da decisão e do comportamento), sendo dotado de consciência de si e de consciência de ser consciente (auto-referência e reflexividade) e de uma linguagem capaz de possibilitar comunicação de indivíduo a indivíduo (MORIN, 1986).

Essas dimensões humanas comportam um tipo de organização no qual o todo é constituído por individualidades que trazem, no âmago da singularidade de cada um, toda a humanidade, toda a vida. Nessa perspectiva hologramática, parte e todo permitem ligações e desconexões, numa totalidade cercada de incertezas e de indeterminações ${ }^{2}$.

Em Freire, essa natureza multidimensional caracteriza-se pela capacidade que os seres humanos têm de apreender o mundo, não só por meio do conhecimento cognitivo mas, também, pela valorização de outros saberes além dos científicos, que se expressam no diálogo fundamentado no pensar ético e na ação política comprometida com o "outro" e que derivam de carências, misérias e sofrimentos profundos e/ou de alegrias, êxtases e prazeres, que vão além das palavras.

Essas noções são encontradas em Freire (1967) quando salienta que os seres humanos são seres históricos que falam ao mundo e que, ao se tornarem autores, 
mudam o mundo. Freire acredita que a realização humana depende do grau de inserção crítica de cada um na realidade, que o firmará como um sujeito de opções e de modificações, possibilitando-lhe atingir seu objetivo de humanização, mediante a transformação da realidade. Essa postura autônoma, aberta e fechada a um só tempo, permite a interação do ser humano com o ambiente, ao mesmo tempo em que preserva a sua individualidade. $\mathrm{Na}$ perspectiva humanista salientada por Freire, esta postura garante que os seres humanos neguem a dominação, a manipulação e a reificação, e que assumam o sujeito que busca como o próprio homem que realiza, em suas relações com o mundo e com os outros. Entretanto, essa garantia depende do desvelamento da realidade e de ir à raiz da essência humana, que ocorre a partir da sensibilização dos sujeitos em sua práxis e no ato de ação-reflexão-ação que, para Freire, se traduz no compromisso histórico enquanto ato de amor pelo mundo, pela vida e pelos seres humanos. Em suas palavras: "É também consciência histórica: é inserção crítica na história, implica que os homens assumam o mundo" (FREIRE, 1980, p. 26).

Nesse processo de conversão de produtor em produto e de produto em produtor, que de causa torna-se efeito e vice-versa, pode-se compreender, ainda que de forma relativa, a autonomia do indivíduo. Para Morin (1996), a noção de autonomia, intrinsecamente ligada à noção de dependência energética, informativa e organizativa do mundo exterior, é inseparável da noção de eco-auto-organização. Nesta noção articula-se, em contraposição à ideia linear de que toda causa tem um efeito, o princípio de recursividade organizacional (ALMEIDA, 1997) que sugere que os seres humanos são, ao mesmo tempo, produtos e produtores da sociedade. Nesse sentido, Morin afirma que "o conhecimento está ligado, por todos os lados, à estrutura da cultura, à organização social, à práxis histórica. Ele não é apenas condicionado, determinante e produtor ..." (1998, p. 31). Acrescenta, ainda, que

a sociedade é, sem dúvida, o produto de interações entre indivíduos. Essas interações, por sua vez, criam uma organização que tem qualidades próprias, em particular a linguagem e a cultura. E essas mesmas qualidades retro-atuam sobre os indivíduos desde que vêm ao mundo, dando-lhes linguagem, cultura etc. Isso significa que os indivíduos produzem a sociedade, que produz os indivíduos (1996, p. 48).

Essa reflexão sobre a autonomia-dependência do indivíduo remete a ideia do sujeito como estrutura organizadora que incorpora as dimensões biológica, cognitiva, afetiva e os princípios de identidade, liberdade, transcendência, incerteza e intercomunicação, que liga o "eu" ao nós, ao "si" e a "isto". Esse último pressupõe que um diálogo autêntico se baseia na relação entre dois seres humanos históricos, leitores e escritores do mundo. Esse processo dialógico permite a construção da humanização desses sujeitos e sua consequente emancipação.

Pensar o sujeito em suas ambivalências, incertezas e insuficiências, reconhecendo ao mesmo tempo seu caráter central e periférico, significante e significado, demanda uma reforma do pensamento que, segundo Morin, é capaz de unir conceitos considerados antagônicos (universalidade e singularidade) e de gerar um pensamento do contexto e do complexo. 
Essa interligação entre individualidades fundamenta uma solidariedade cósmica de base, na medida em que os seres vivos necessitam uns dos outros para existirem, relacionando-se como em uma teia, em que diversos graus de interação e de intensidade energética geram uma complexidade e demandam uma lógica capaz de compreender a totalidade do processo cósmico - a lógica dialógica. A ideia de dialogicidade pressupõe que para se compreender alguns fenômenos é necessário juntar duas noções que a princípio são antagônicas e, ao mesmo tempo, complementares. A definição de "vida como conjunto de forças que resistem à morte", dada pelo cientista Bichat no século XIX, postula a integração entre o ciclo da vida e o ciclo da morte, tanto dos seres vivos como da sociedade, na substituição de células mortas por outras vivas e na transmissão de cultura às novas gerações (MORIN, 1997). Com essa lógica, Morin identifica a possibilidade de se compreender a complementaridade no antagonismo e postula o surgimento de organizações e de sistemas a partir da relação dialógica das noções de ordem e desordem, energia e matéria, caos e cosmos, partícula e onda, homo sapiens e homo demens, vistas como dimensões de uma mesma realidade (PENA-VEGA et al, 2001).

De igual modo em Freire, essa possibilidade estende-se para o domínio humano, concebendo o encontro amoroso entre sujeitos incompletos, inquietos e em busca permanente de um conhecimento da realidade para transformá-la, como o cumprimento da vocação ontológica de humanização que se liga aos princípios de fraternidade e de solidariedade cósmica. A busca em comunhão, baseada na cooperação e na cumplicidade, assim como, na tolerância, na compaixão e no amor, intrínsecos à filosofia e ao método de educação de adultos de Paulo Freire, reflete as bases do pensamento complexo, fundamentadas nas noções de integração e de complementaridade. ${ }^{3}$

O compromisso político do profissional da educação com a sociedade, em Freire postulado como transcendentalidade, constitui-se dessa consciência histórica e coletiva que, por se estender para além da consciência individual e ser aberta ao diálogo, é capaz de projetar uma ação historicamente viável, a partir de sua vocação ontológica de humanização e de seu comprometimento com o processo de transformação social, num movimento de ação-reflexão-ação que integra o sujeito ao objeto do conhecimento, a natureza à cultura e o processo de aprendizagem às experiências concretas de vida.

Esse compromisso com o mundo pressupõe, segundo Freire, uma experiência humana de ser-no-mundo, numa perspectiva de abertura à intersubjetividade, mediante o diálogo (GADOTTI, 2003). Um ser de relações, consciente de sua temporalidade e de sua incompletude, que busca em comunhão e responde a desafios, sabendo que "ninguém é, se proíbe que outros sejam" (FREIRE, 1967, p. 4). Mas, para que esse diálogo seja autêntico, é preciso que esteja impregnado de amor entre os homens e não de medo e dominação; de humildade e não de arrogância; de esperança na instituição de uma ordem justa e de fé crítica no poder que cada ser tem de fazer e refazer, de criar e recriar o mundo e a si mesmo (FREIRE, 1980). Construído solidariamente contra a desumanização, o diálogo apresenta-se como ato de liberdade e como compromisso com a superação da condição de dominação e de exclusão social (ALMEIDA et al., 2003). 
Esta concepção freireana conjuga-se à ecologia da ação e à ética política que supõem, no pensamento complexo (MORIN, 1998), a restauração do sujeito responsável, consciente e compromissado com a construção de uma ética de religação, que engloba tudo o que une, associa, solidariza-se, fraterniza, opondo-se ao que fragmenta, divide e reduz; com a ética do debate; com a ética da compreensão, da magnanimidade, da generosidade e da resistência contra a barbárie ${ }^{4}$.

\section{O desafio da formação do sujeito transdisciplinar na recria- ção no processo educacional}

No século XXI, há cada vez maior evidência de que a excessiva ênfase no método científico e no pensamento racional, analítico, levou a práticas desarticuladas, resultando em uma dificuldade de percepção do conjunto que, na área educacional, se expressa por uma fragmentação do conteúdo trabalhado nas atividades pedagógicas. A superação dessa abordagem e a incorporação da definição do indivíduo como ser sociocultural pressupõe a transgressão dos limites das abordagens disciplinares e a possibilidade de cooperação entre os saberes construídos no confronto com os paradoxos do mundo - ordem/desordem, parte/todo, singular/geral.

Esse novo espírito científico, capaz de permitir a convivência com a contradição e com a desordem, e de incorporar o acaso e a indeterminação, a incerteza e o particular à análise científica, integrando-a a natureza evolutiva do mundo e colocando-a diante do tempo e do fenômeno complexo, constitui um desafio a ser superado pelos profissionais da educação.

A desconstrução da educação como adestramento e a consciência do papel do educador como mediador no processo de produção de um conhecimento complexo, múltiplo e contraditório e como referência na formação da estrutura de pensamento do sujeito histórico vem ao encontro do perfil do educador que assume a postura dialógica na prática educativa e que exercita a transdisciplinaridade pela via da partilha e da co-produção.

Essa ótica transdisciplinar de visualizar o mundo em processo de mutação prevê que a passagem de um nível de realidade para outro é assegurada pela lógica do terceiro incluído, que leva em conta a contradição e a inclusão do terceiro termo de uma proposição, e que a estrutura da totalidade dos níveis de realidade ou percepção é complexa, tendo em vista que cada nível é o que é porque todos os níveis existem ao mesmo tempo (NICOLESCU, 1999).

Ao postular a complexidade como um dos pilares da Transdisciplinaridade, junto com os níveis de realidade e a lógica do terceiro incluído, Nicolescu destaca-a como uma teoria que permite ao cientista conceber a realidade dos fenômenos em diversas dimensões, na qual os problemas se manifestam cada vez mais polidisciplinares, transversais, multidimensionais, transnacionais, globais e planetários. A validade da transdisciplinaridade para o campo da educação e da cultura, tal como em Paulo Freire, é reforçada por esse autor ao afirmar que: 
a educação transdisciplinar é uma educação de libertação, que nos permitirá estabelecer vínculos entre pessoas, fatos, imagens, campos do conhecimento e da ação, possibilitando descobrir o Eros da aprendizagem durante toda a vida, e construir seres humanos em constante questionamento e constante integração (NICOLESCU, 2003, p. 56).

Nesse papel, o educador assume a missão de problematizador, por meio do recurso do pensamento interrogativo, contra os dogmatismos, ideias preconcebidas, falsas evidências, contribuindo para obstaculizar a possibilidade de manipulação a que o sujeito está submetido. A problematização pressupõe atitude reflexiva, exercício da curiosidade e da dúvida, arte da discussão e da argumentação, sagacidade, atenção constante, desenvoltura, senso de oportunidade. Além disso, reconhece a postura crítica como forma de revisar conceitos e paradigmas, com base no princípio da indeterminação ou da incerteza. Segundo Frei Betto (1997), este princípio encontra-se não somente nas partículas subatômicas, mas, também, nos seres humanos, por serem dotados de livre-arbítrio. Esta liberdade se expressa na capacidade de escolha entre várias alternativas (MORIN, 1996) e, longe de desencorajar a ação, encaminha os sujeitos a uma prática participativa e solidária, reconhecendo e respondendo a essa incerteza em uma ecologia da ação, a partir da ética da tolerância, que se funda nos pressupostos democráticos, no princípio da livre-expressão e no postulado enunciado por Neils Bohr, de que "o contrário de uma verdade profunda não é um erro, mas outra verdade profunda”(MORIN, 1997, p. 24).

Assumir uma constante reflexão requer do educador a renovação de seus próprios pensamentos e da sua função no processo de ensino-aprendizagem. De autoridade detentora do saber, o educador passa a mediador capaz de contribuir para que o educando, considerado ser em devir, produza seu conhecimento a partir da história, das experiências e de sua própria cultura, estimulado a pensar e a caminhar de forma independente, e a criar, ao invés de acumular saberes acriticamente, como mero depositório bancário a serviço do opressor, cuja educação nega o conhecimento como processo de procura e de emancipação. Em Freire,

a educação problematizadora está fundamentada sobre a criatividade e estimula uma ação e uma reflexão sobre a realidade, respondendo assim à vocação dos homens que não são seres autênticos senão quando se comprometem na procura e na transformação criadoras (1980, p. 81).

A relação conhecimento, cultura e sociedade, sugerida por Morin (1998) como tronco comum indistinto, manifesta-se no método Paulo Freire com o estabelecimento dos Círculos de Cultura ${ }^{5}$ e com a escolha dos temas/palavras geradoras na realização do trabalho de alfabetização de adultos. Ponto de partida do processo alfabetizador, as palavras geradoras, oriundas do universo vocabular do alfabetizando, apresentam ricas possibilidades fonêmicas e grande carga semântica, permitindo combinações dos elementos básicos, formação de outras palavras, domínio do universo da palavra escrita, transfiguração pela crítica e engajamento de quem a pronuncia na ação transformadora do mundo. Representações de significações constituídas de comportamentos de situações existenciais, essas palavras, quando expostas na lousa, permitem 
objetivação do mundo do alfabetizando, admiração de sua experiência, construção de uma postura crítica e reaproximação com os companheiros do Círculo de Cultura. Nesse Círculo, o que importa é que os "seres individuais concretos" se reconheçam como criadores de cultura assumindo a sua liberdade e estabelecendo relações democráticas no contexto educativo e no contexto social. Esse processo, de passagem da compreensão ingênua do mundo à compreensão crítica da realidade, pressupõe uma introdução ao conceito de cultura em que o ser humano torna-se criador e autor do mundo.

Para Freire, a adoção da temática da realidade como forma de aproximação do conhecimento à cultura e à sociedade refere-se ao pressuposto de que "procurar o tema gerador é procurar o pensamento do homem sobre a realidade e a sua ação sobre esta realidade que está em sua práxis” (1980, p. 52). Na percepção desse autor, na medida em que os seres humanos assumem uma atitude ativa na exploração de suas temáticas, sua consciência crítica da realidade se aprofunda e tende a denunciar as contradições ali existentes o que o torna, inclusive, mais comprometido com o real, pois "ao perceber-se como testemunha de sua história, sua consciência se faz reflexivamente mais responsável dessa história" (1983, p. 7). Nesse sentido, "a procura temática converte-se assim numa luta comum por uma consciência de si, que faz desta procura o ponto de partida do processo de educação e de ação cultural do tipo libertador" (FREIRE, 1980, p. 33).

A educação que visa ao desenvolvimento do ser humano, à constituição do sujeito capaz de tornar-se co-autor de si mesmo, ao mesmo tempo em que forma o cidadão integral, oferece, para o pensamento complexo, um campo teórico e terreno de práticas férteis. Isto porque, ultrapassar a função de simples instrutores, que visa à adaptação do sujeito à sociedade e às regras pré-estabelecidas mantenedoras do status quo, para estimular algo além do saber e do saber fazer - um saber ser e estar no mundo capaz de fomentar o estabelecimento de elos integrativos e de redes interativas, é objetivo dos educadores que partilham da percepção da necessidade de se relacionar educação e cultura nos processos de ensino-aprendizagem, como forma de enfrentar os desafios constituídos pelas contradições e pelos antagonismos verificados nas diversas percepções da realidade, nesse momento histórico.

\section{À guisa de apontamentos indicativos: o desafio da forma- ção do sujeito transdisciplinar}

O sujeito que se encontra diante da necessidade de reformular seus pensamentos, valores, percepções, relações e atitudes, na perspectiva de superar o impasse traduzido pelo paradigma da modernidade que compartimentaliza o conhecimento em disciplinas e especializações, reduz o complexo ao simples e separa a cultura da natureza, considerando os fenômenos vivos e sociais a partir de uma causalidade linear e de uma concepção mecanicista/determinista que encobre o que é subjetivo, afetivo, espiritual e criador, atualmente é responsável pela construção de uma política de civilização pautada em uma renovada consciência coletiva, saturada de complexidade. 
Restabelecer as articulações entre conhecimento científico e saber tradicional, cultura e natureza, sujeito e objeto, numa tentativa de perceber a multidimensionalidade da realidade, demanda a geração de um conhecimento contextualizado capaz de fazer emergir novos saberes e formas de dialogar, interpretar e agir no mundo.

Em busca da síntese da complexidade do pensamento freireano, arvoramonos a pensar que sua proposta pretende compreender o mundo presente, para o qual um dos imperativos é a unidade do conhecimento. Freire enfatiza a necessidade de considerar e de trabalhar as características dos lugares, com seus princípios e cultura, contextualizando o conteúdo educacional para traduzir as bases do conhecimento para uma práxis local. Tanto Freire quanto Morin alinham-se na necessidade de se encadear o conteúdo tratado na educação levando-se em conta a complexidade envolvida. Também Nicolescu, com a abordagem transdisciplinar, reclama uma visão diversa apreendida através da consideração de diferentes níveis de realidade e de diversificados níveis de percepção e de consciência.

A relevância da contextualização torna-se imperativa na medida em que é através dela que as possibilidades e as demandas sociais penetram no processo educativo e nas práticas de pesquisa, influenciando a formulação dos problemas, a implementação de soluções, a avaliação de resultados e, sobretudo, a transformação promovida nas pessoas e nos espaços sociais. Assim, mais uma vez fica ressaltado o quanto é mandatória a comunicação de mão dupla entre as comunidades e os processos educacionais para a produção e a disseminação da filosofia da práxis.

É fundamental destacar que estabelecer cooperação e extrair consenso é difícil, mas quando as comunidades ganham voz nos processos educativos, os problemas são percebidos em sua complexidade e requerem mais atores cruzando um alargado espectro de "mundos" sociais e de pontos de vista. Este comportamento demanda uma nova perspectiva de engajamento entre educadores e comunidades onde atuam, apoiados em configurações transdisciplinares.

\section{Referências}

ALMEIDA, M. C. Complexidade, do casulo à borboleta. In: CASTRO, G. et al. (org). Ensaios de Complexidade. Porto Alegre: Sulina, 1997, p. 25-45.

ALMEIDA, M.C.; KNOBB, M.; ALMEIDA, A. M.(org.). Polifônicas Ideias. Porto Alegre: Sulina, 2003.

BETTO, F. Indeterminação e Complementaridade. In: CASTRO, G. (org.) et al. Ensaios de Complexidade. Porto Alegre: Sulina, 1997, p. 47-53.

BOHR, N. Física atômica e conhecimento humano: ensaios 1932-1957. Rio de Janeiro: Contraponto, 1995.

FREIRE, P. Papel da educação na humanização. Trad. Carlos Souza. Universidade do Chile, Santiago, mai./1967.

FREIRE, P. Conscientização: teoria e prática da libertação - uma introdução ao pensamento de Paulo Freire. Ed. Moraes, 1980.

FREIRE, P. O compromisso do profissional com a sociedade. In: Educação e Mudança. Rio de Janeiro: Paz e Terra, 1983. 
FREIRE, P. Pedagogia do Oprimido. 13a ed. Rio de Janeiro. Paz e Terra. 1983.

GADOTTI, M. Saber aprender: um olhar sobre Paulo Freire e as perspectivas atuais da educação. In: LINHARES, C.; TRINDADE, M. N. (orgs.) Compartilhando o mundo com Paulo Freire. São Paulo: Cortez: Instituto Paulo Freire, 2003, p. 107-125. (Biblioteca freiriana; v.7)

HEISENBERG, W. Física e filosofia. Brasília: Editora Universidade de Brasília, 4a ed. - Edições Humanidades, 1998. (Série Métis).

MORIN, E. Epistemologia da Complexidade. In: SCHNITMAN, D. F. (org.). Novos paradigmas, cultura e subjetividade. Porto Alegre: Artes Médicas, 1996, p.274-286.

MORIN, E. A noção de sujeito. In: SCHNITMAN, D. F. (org.). Novos paradigmas, cultura e subjetividade. Porto Alegre: Artes Médicas, 1996, p. 45-58.

MORIN, E. A ética do sujeito responsável. In: CARVALHO, E. A. et al. Ética, Solidariedade e Complexidade. São Paulo: Palas Athena,1998, p.65-76.

MORIN, E. Ciência com Consciência. 2a ed., Rio de Janeiro: Bertrand Brasil, 1998.

MORIN, E. O Método I: a natureza da Natureza. $3^{a}$ ed., Portugal: Publicações Europa-América, Biblioteca Universitária, 1977.

MORIN, E. O Método III: o conhecimento do conhecimento. Portugal: Publicações Europa -América. Éditions Du Seil, 1986.

MORIN, E. Abertura. Complexidade e ética da solidariedade. In: Ensaios de complexidade. Coordenação de Gustavo de Castro (org) et. al. Porto Alegre: Sulina, 1997, p.11-12.

NICOLESCU, B. O manifesto da transdisciplinaridade. São Paulo: TRIOM, 1999.

NICOLESCU, B. Para uma educação transdisciplinar. IN: LINHARES, C. e TRINDADE, M. N. (orgs.) Compartilhando o mundo com Paulo Freire. São Paulo: Cortez: Instituto Paulo Freire, 2003, p. 41-71. (Biblioteca freiriana; v.7).

PENA -VEGA, Alfredo; ALMEIDA, Cleide R.S. de; PETRAGLIA, Izabel (orgs.). Edgar Morin: ética, cultura e educação. São Paulo: Cortez, 2001.

SIMÕES, J.A ideologia de Paulo Freire. São Paulo: Loyola, 1974.

TORRES, C. A. A dialética hegeliana e o pensamento lógico-estrutural de Paulo Freire. In: Síntese, Nova Fase, no7, São Paulo: Edições Loyola, 1976.

\section{Notas}

${ }^{1}$ A ideia de complexidade tem origem dispersa, mas credita-se a Edgar Morin o papel de grande artesão do pensamento complexo sendo, hoje, o Presidente fundador da Association pour la Pensée Complexe. As reflexões a respeito da complexidade apresentadas neste artigo foram traçadas, prioritariamente, a partir das análises deste autor em algumas de suas obras.

${ }^{2}$ O princípio da incerteza, formulado por Werner Heisenberg, em 1927, demonstra que as imutáveis e previsíveis leis da natureza não se aplicam na esfera do infinitamente pequeno, pois é impossível observar os eventos do mundo subatômico submetidos que estão, seja velocidade e posição, momento e energia, por exemplo, a resultados que permanecem no limite da incerteza (HEISENBERG, 1998).

${ }^{3} \mathrm{Na}$ perspectiva do princípio de complementaridade estabelecido por Niels Bohr, em 1913, a natureza apresenta-se, no mundo quântico, de forma dual e dialógica. Dual sob o ponto de vista de interação e não dualista, no sentido platônico. Essa aparente dualidade apresentada pela matéria, no interior do átomo, manifesta-se em seu comportamento ora como partícula, com trajetória bem definida, ora como onda, in- 


\section{Elza Maria Neffa Vieira de Castro - Krishna Neffa Vieira de Castro}

teragindo sobre si mesma. Postulando a complementaridade entre onda e partícula, energia e matéria, Bohr refuta o dogma da neutralidade cientifica ao entender que há uma interrelacão entre observador e observado, uma conexão entre a consciência e a realidade (BOHR, 1995).

${ }^{4}$ Essas éticas são enunciadas por Edgar Morin como ideias-guia contidas na ética política que restaura o sujeito responsável.

${ }^{5}$ Círculo de cultura é uma unidade de ensino que substitui a escola tradicional e reúne um coordenador com algumas dezenas de homens do povo, num trabalho de conquista da linguagem (Freire, 1980, p. 50).

* Professora doutora da Universidade do Estado do Rio de Janeiro, Rio de Janeiro, Rio de Janeiro, Brasil.

** Pós-Doutorando em Meio Ambiente pela Universidade do Estado do Rio de Janeiro, Rio de Janeiro, Rio de Janeiro, Brasil.

\section{Correspondência}

Elza Maria Neffa Vieira de Castro - Universidade do Estado do Rio de Janeiro, Faculdade de Educação. Rua São Francisco Xavier, 524 - 12º andar sala 12005 Bloco F, Maracanã. CEP: 20550013. Rio de Janeiro, Rio de Janeiro, Brasil.

E-mail: elzaneffa@gmail.com - krishnaneffa@gmail.com

Recebido em 19 de maio de 2017

Aprovado em 20 de março de 2018 